\title{
MATRIX DESIGN OF A NOVEL DUCTILE CAST IRON MODIFIED BY W AND AI: A COMPARISON BETWEEN THERMODYNAMIC MODELING AND EXPERIMENTAL DATA
}

\author{
Gülşah Aktaş Çelik ${ }^{l *}$, Maria-Ioanna T. Tzini ${ }^{2}$, Şeyda Polat ${ }^{l}$, \\ S. Hakan Atapek ${ }^{l}$, Gregory N. Haidemenopoulos ${ }^{2,3}$ \\ ${ }^{1}$ Kocaeli University, Department of Metallurgical and Materials Engineering, Kocaeli, \\ Turkey \\ ${ }^{2}$ University of Thessaly, Department of Mechanical Engineering, Volos, Greece \\ ${ }^{3}$ Khalifa University of Science \& Technology, Department of Mechanical Engineering, \\ $U A E$
}

Received 17.10.2019

Accepted 02.03.2020

\begin{abstract}
In high-temperature applications of ferrous materials, as in the case of exhaust manifolds, high thermal and mechanical stability are required. Stainless steels and Niresist alloys having austenitic matrices are good candidates to meet these requirements at elevated temperatures; however, they are expensive materials and present difficulties in casting. Ferritic ductile cast irons, like the commercial SiMo alloy, are comparatively cheaper materials with better castability, but they cannot be used above approximately $800{ }^{\circ} \mathrm{C}$. Thus, to meet the requirements with low-cost materials having improved hightemperature properties, new alloys must be developed by ferrite forming elements having the potential to increase equilibrium temperature. In this study, initially, a novel ductile cast iron matrix was designed using $1 \mathrm{~W}$ and $0-4 \mathrm{Al}$ wt.- $\%$ and their phases stable at room temperature, transformation temperatures, solidification sequences and thermal expansivity values were determined using thermodynamic calculations with ThermoCalc software. Computational studies revealed that (i) designed alloy matrices had graphite and $\mathrm{M}_{6} \mathrm{C}$ type carbides embedded in a ferritic matrix at room temperature as expected, (ii) $\mathrm{A}_{1}$ temperature increased as aluminum content increased. The obtained values were all above that of commercial SiMo alloy, (iii) the detrimental effect of increased aluminum addition on graphite content, and thermal expansivity was observed. Secondly, microstructural and thermal characterizations of cast alloys were performed for validation - the obtained data were in good agreement with the thermodynamic calculations.
\end{abstract}

*Corresponding author: Gülşah Aktaş Çelik, gulsahaktas@gmail.com 
Keywords: alloy design; Thermo-Calc; ductile cast iron; microstructure; characterization.

\section{Introduction}

Exhaust manifolds deliver hot and oxidative exhaust gases from the combustion chamber to the atmosphere [1, 2]. Initial exhaust manifolds were manufactured using unalloyed high carbon grey cast irons that could be used at operating temperatures up to $540{ }^{\circ} \mathrm{C}[3]$. Due to the increase in the power density of new engines, manufacturers are in search of new materials for exhaust manifolds that can withstand temperatures above $950{ }^{\circ} \mathrm{C}$ [4-8]. Such materials must have high thermal conductivity, high oxidation resistance, low thermal expansion coefficient and mechanical stability at elevated temperatures [3]. Austenitic stainless steels and austenitic ductile cast irons (Ni-resist alloys) are good candidates to meet these requirements [6-8]. However, they are expensive materials and present difficulties in casting due to high solidification temperatures [9]. The SiMo cast irons having a ferritic matrix are comparatively cheaper materials with better castability [4, 10]. Besides, the ferritic matrix provides higher thermal conductivity and lower thermal expansion coefficient compared to the austenitic one [3]. High thermal conductivity provides fast cooling; thus, the material is subjected to high temperatures for shorter periods $[11,12]$. Low thermal expansion coefficient is vital for long service life avoiding cracks that may form due to thermal fatigue [4, 13]. Despite all the mentioned qualities, ferritic ductile cast irons cannot be used above their transformation temperature from austenite to ferrite $\left(A_{1}\right)$ which limits their use above approximately $800^{\circ} \mathrm{C}[14]$. Thus, it will be beneficial to increase $A_{1}$ temperature by using modification elements like $\mathrm{Si}, \mathrm{Nb}, \mathrm{W}, \mathrm{Al}, \mathrm{Cr}$ etc. [15]. On the other hand, it is essential to consider the effect of alloying elements on graphite distribution and morphology since it directly affects the mechanical and thermal properties. Despite providing the best mechanical properties, spheroidal graphite exhibits lower conductivity than vermicular and flake graphite [11-13, 16-18]. According to the literature, $\mathrm{Si}$ and $\mathrm{Al}$ promote the graphite formation and increase nodule count as well as stabilize ferrite due to their high solubility in that phase [19-21]. Alloying elements like $\mathrm{Al}$ [22], $\mathrm{Ti}$ [23], and $\mathrm{Nb}$ [24] affect the graphite morphology by changing it from spheroidal to vermicular. Mechanical properties are also affected by the addition of alloying elements. Some carbide forming elements (such as $\mathrm{Mo}, \mathrm{W}$, and $\mathrm{Nb}$ ) can be added in small quantities (up to 1 wt.-\%) to improve mechanical properties since these elements provide precipitation strengthening by carbides and also prevent grain boundary motion and refine grain size [8, 24-26]. In this study, a novel ductile cast iron composition $3.5 \mathrm{C}, 4 \mathrm{Si}, 1 \mathrm{~W}$ wt.- $\%$ was selected as the main composition. In order to obtain a hypereutectic composition which is useful for casting and solidification, carbon and silicon amounts determining the carbon equivalent were selected as 3.5 and 4 wt.-\%, respectively. In the designed matrix, tungsten was used instead of molybdenum, since tungsten is both ferrite and carbide forming element and provides oxidation resistance. In order to increase the $A_{1}$ temperature, aluminum additions up to 4 wt.- $\%$ were made to the main composition since higher aluminum levels are known to affect the graphite morphology adversely [22], and therefore thermal properties [16-18]. Thermodynamic calculations on these compositions were carried out employing Thermo-Calc software and the results were validated by experimental studies to investigate the possibility of their use in place of commercial ferritic ductile cast irons at more demanding working conditions. 


\section{Experimental work}

Thermodynamic calculations for the composition of $3.5 \mathrm{C}, 4 \mathrm{Si}, 1 \mathrm{~W}, 0-4 \mathrm{Al}$ (wt.$\%)$ were carried out with Thermo-Calc software. The TCFE6 database was used in order to determine $A_{1}$ temperatures of the studied compositions, the mole fraction of graphite, phases stable at room temperature (RT), and thermal expansivity of ferrite. Solidification sequences of the compositions were studied using the Scheil module.

After calculations, in order to validate to computed values, $3.5 \mathrm{C}-4 \mathrm{Si}-1 \mathrm{~W}-x \mathrm{Al}$ alloys (wt.-\%) were produced as Y block by sand mold casting, according to ASTM A 536-84 standard. For this process, $5 \mathrm{~kg}$ charge was prepared with nodular pig iron (MMM International Trading Co., 4.30C-0.7Si-0.06Mn-0.05P-0.018S wt.-\%), ferrosilicon (MMM International Trading Co., 72Si-1.50Al-0.10C-0.02S-0.024P wt.-\%), ferrotungsten (70W-0.5Mn-1Si-0.06S-0.25C wt.- $\%$ ) and DIN 1020 steel. The used materials for the charge were all commercial materials. The charge was melted in the 35 $\mathrm{kW}$ Inductotherm induction furnace with a capacity of $25 \mathrm{~kg}$. Just before the melting process was completed, pure aluminum was added according to the chosen composition. The melting process was completed at $1560{ }^{\circ} \mathrm{C}$, followed by spheroidization process which was carried out in a $\mathrm{SiC}$ crucible. For spheroidization process, the nucleation agent (FerroPem, 75Si-0.94Ca-1.68Ce-0.89Al wt.-\%) and magnesium-rich alloy FeSiMg (Snam Alloys Pvt. Ltd., 45Si-7Mg-0.56Al-1.15Ca-1.18R wt.-\%, $R$ : rare earth) for spheroidization were put at the bottom of the crucible before pouring the charge. A sample from the molten alloy, after spheroidization, was taken by pouring it into a copper mold, in order to verify the chemical composition by optical emission spectrometer (OES, Foundry Master) and then the rest of the molten metal was cast into the sand mold. In order to specify the cast alloys, systematic coding is preferred. In the coding system, the main composition $(3.5 \mathrm{C}, 4 \mathrm{Si}, 1 \mathrm{~W}$ wt.- $\%)$ is coded as specimen $0 \mathrm{Al}$ and the others are coded as $1 \mathrm{Al}, 2 \mathrm{Al}, 3 \mathrm{Al}$ and $4 \mathrm{Al}$ for 1, 2, 3 and $4 \mathrm{wt.}-\% \mathrm{Al}$ additions, respectively.

Both microstructural examinations and thermal analyses were applied to the cast alloys in order to validate the computational results in terms of (i) formation of the phases during solidification, (ii) critical temperatures, and (iii) phases stable at RT. For microscopic examinations, as-cast alloys were prepared by metallographic methods. Microstructural characterization was carried out using both light microscope (LM, Olympus BX41M-LED), scanning electron microscope (SEM, Jeol JSM 6060) and energy dispersive spectrometer (EDS, IXRF). Phases present were also identified by xray diffraction (XRD, Rigaku Ultima+). XRD studies were carried out with $\mathrm{Cu}-\mathrm{K}_{\alpha}$ radiation and a scanning speed of $1.0 \% \mathrm{~min}$. The determined phases were quantified according to ISO 945-2, by an image analyzer (IA, Leica Las V4.12). Thermal analysis was carried out by using a differential thermal analyzer (DTA, Netzsch STA 409 PG Luxx). The DTA tests were carried out under vacuum, $\mathrm{Al}_{2} \mathrm{O}_{3}$ crucibles were used and a calibration was performed as follows: (i) heating to $1460{ }^{\circ} \mathrm{C}$ at a rate of $5{ }^{\circ} \mathrm{C} \cdot \mathrm{min}^{-1}$, (ii) holding at that temperature for $5 \mathrm{~min}$, (iii) cooling to RT at a rate of $5{ }^{\circ} \mathrm{C} \cdot \mathrm{min}^{-1}$. The samples were tested under these conditions and an empty crucible was used as reference material. 


\section{Results and discussion}

\section{Thermodynamic modeling}

Carbon isopleth concerning a constant $4 \mathrm{Si} 1 \mathrm{~W}$ composition (0Al) is given in Figure 1a, confirming the composition containing $3.5 \% \mathrm{C}$ is hypereutectic. Since some of the phase areas are very narrow in this isopleth, expanded drawings are also illustrated in the same figure. Solidification starts with graphite $(\mathrm{G})$ precipitation from the liquid phase $(\mathrm{L})$ and finishes after austenite (A) transformation. $\mathrm{M}_{6} \mathrm{C}$ carbide starts precipitating at 978 ${ }^{\circ} \mathrm{C}$. Ferrite (F) transformation from austenite starts at $907{ }^{\circ} \mathrm{C}$ and finishes at $853{ }^{\circ} \mathrm{C}$. The stable phases at room temperature appear to be ferrite, graphite and $\mathrm{M}_{6} \mathrm{C}$. In order to understand the effect of aluminum addition on austenite to ferrite phase transformation, aluminum isopleth of 3.5C4Si1 W constant composition is given in Figure 1b. According to this isopleth, the phase transformation sequence remains the same up to $2.7 \mathrm{Al}$ wt.- $\%$. At higher aluminum additions above this composition, ferrite formation from austenite occurs rather than $\mathrm{M}_{6} \mathrm{C}$ precipitation. However, the final microstructure at $\mathrm{RT}$ does not change and consists of ferrite, graphite and $\mathrm{M}_{6} \mathrm{C}$ up to the studied highest aluminum addition. On the other hand, all the transformation temperatures except for the precipitation of $\mathrm{M}_{6} \mathrm{C}$ are increased by increasing aluminum content.

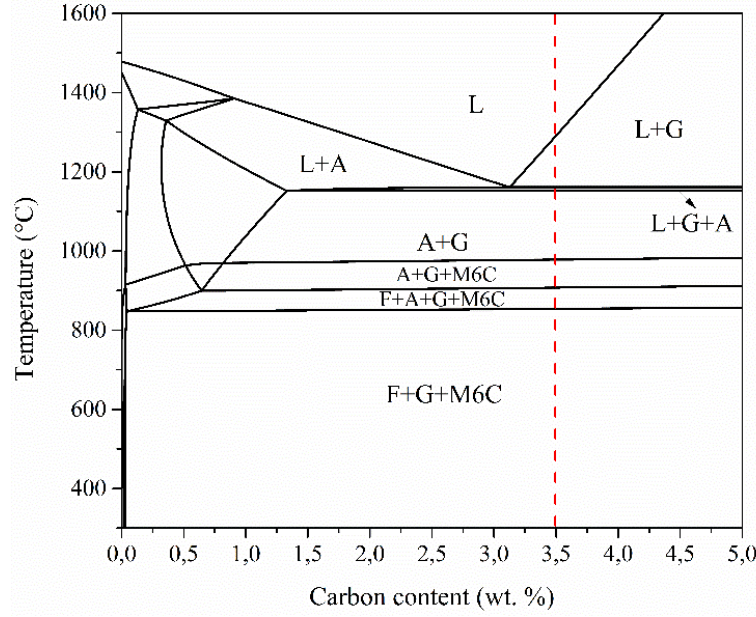

(a)

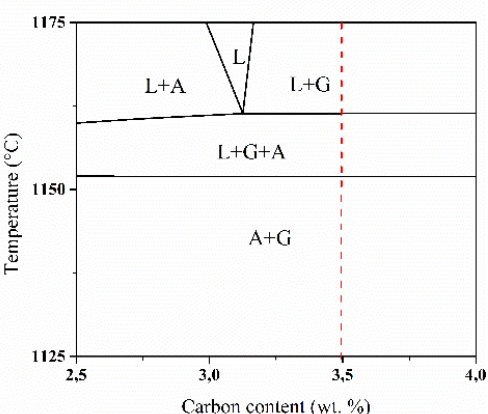




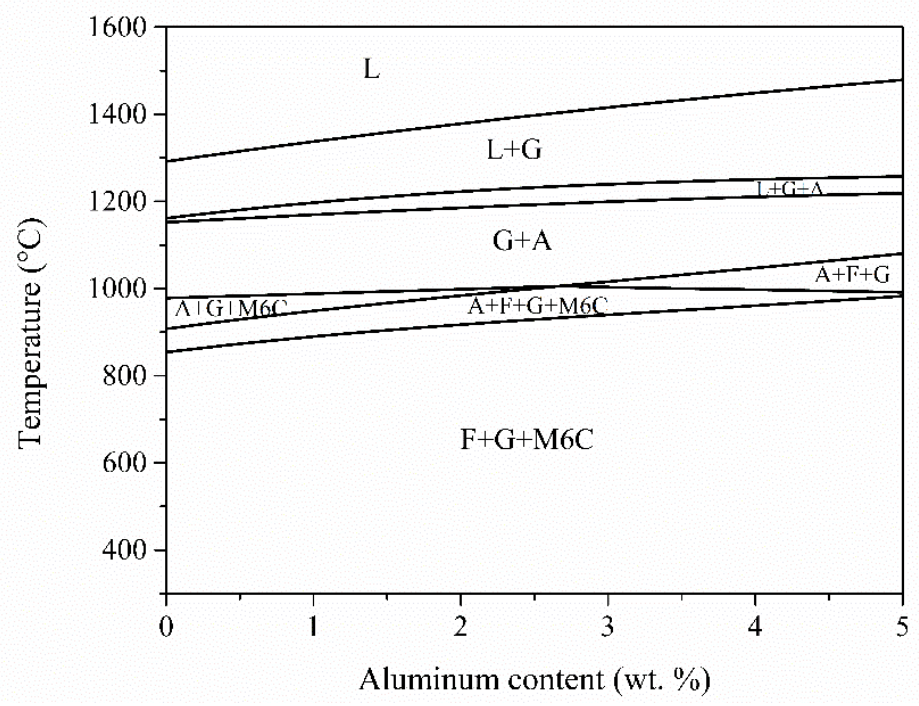

(b)

Fig. 1. (a) C isopleth for OAl alloy and (b) Al isopleth sections.

Thermo-Calc software also provides the amounts of phases for the studied compositions as a function of temperature, and the data for $1 \mathrm{Al}$ and $4 \mathrm{Al}$ are presented in Figure 2 in order to reveal the effect of aluminum addition on amounts of austenite, ferrite, carbide and graphite. It is important to understand the effect of aluminum addition on $\mathrm{A}_{1}$ temperature in order to determine the maximum service temperature of the compositions. Figure 3 shows the variation of $A_{1}$ temperature as a function of aluminum content and the curve clearly indicates that aluminum addition increases the $\mathrm{A}_{1}$ temperature. While $\mathrm{A}_{1}$ temperature of an alloy having no aluminum $(0 \mathrm{Al})$ is $853^{\circ} \mathrm{C}$, it is increased to $960{ }^{\circ} \mathrm{C}$ by the addition of $4 \mathrm{Al} \mathrm{wt} .-\%$. This effect is also reported in dilatometric data of $3.4 \mathrm{C}-3 \mathrm{Si}$ 0.45Mo and 3.1C-3.1Si-0.55Mo-3Al (wt.-\%) alloys studied by Ibrahim et al. and they concluded that $\mathrm{A}_{1}$ temperature was raised by $110{ }^{\circ} \mathrm{C}$ and reached to $960{ }^{\circ} \mathrm{C}$ due to the solubility of aluminum within the ferrite lattice [25].

In calculations, the variation of graphite content as a function of aluminum addition is also studied, and the obtained data is given in Figure 4. The diagram clearly shows that aluminum has a decreasing effect on graphite content. In solidified cast irons, not only segregation but also the accumulation of aluminum atoms around the graphite phases causes nonhomogeneous diffusion of carbon results in a change in the morphology of graphite and its content [25]. Thermal expansivity is another design criterion for the materials used in high-temperature applications and it must be kept low. However, calculations indicated that the thermal expansivity of ferrite at RT increases with aluminum addition (Figure 5). 


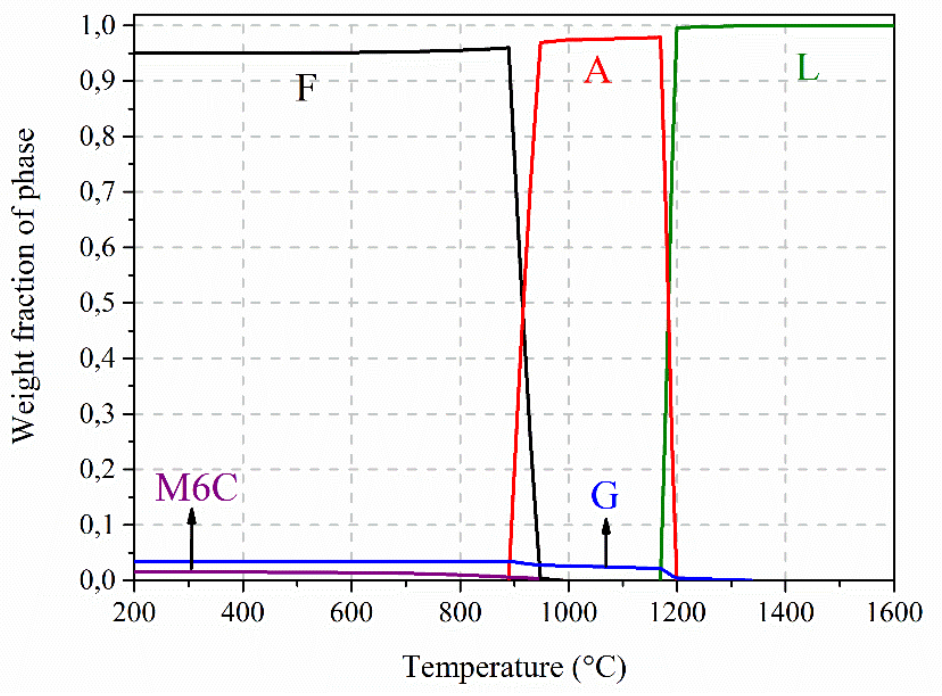

(a)

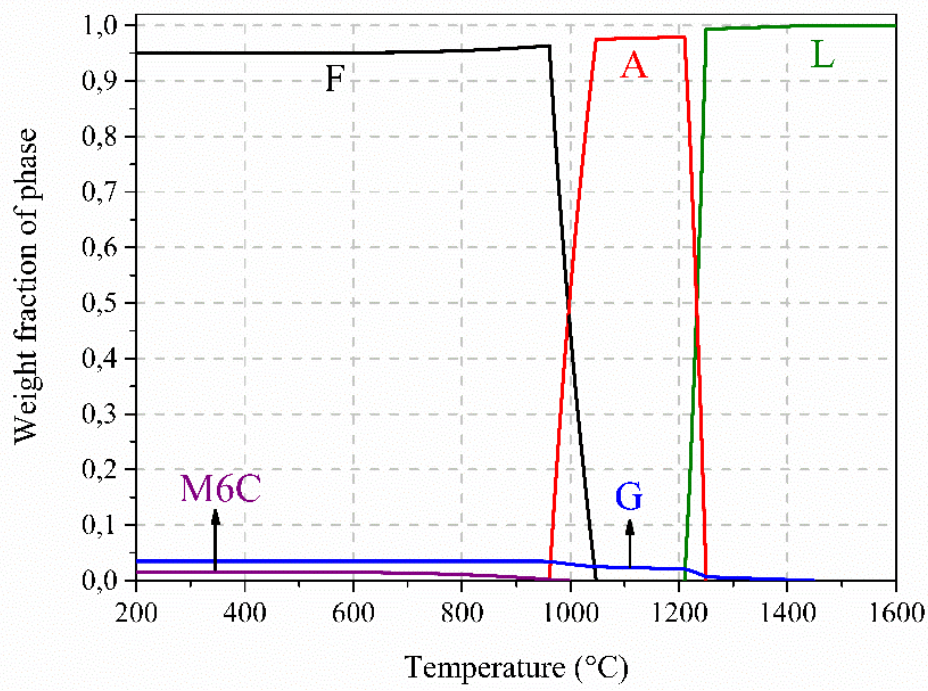

(b)

Fig. 2. Variation of the weight fraction of phases as a function of temperature;

(a) $1 \mathrm{Al}$ and (b) $4 \mathrm{Al}$. 


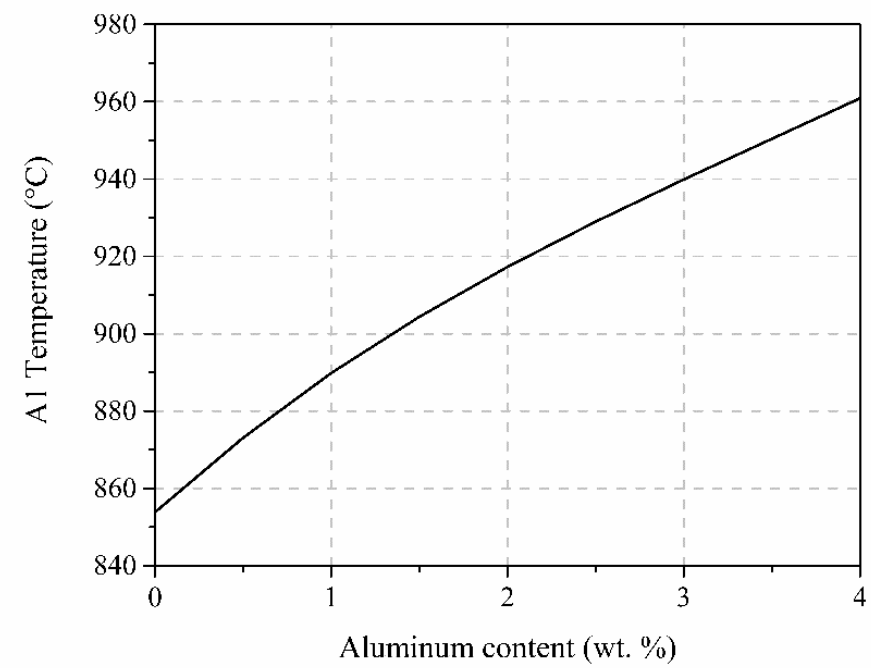

Fig. 3. Change in $A_{1}$ temperature as a function of aluminum addition.

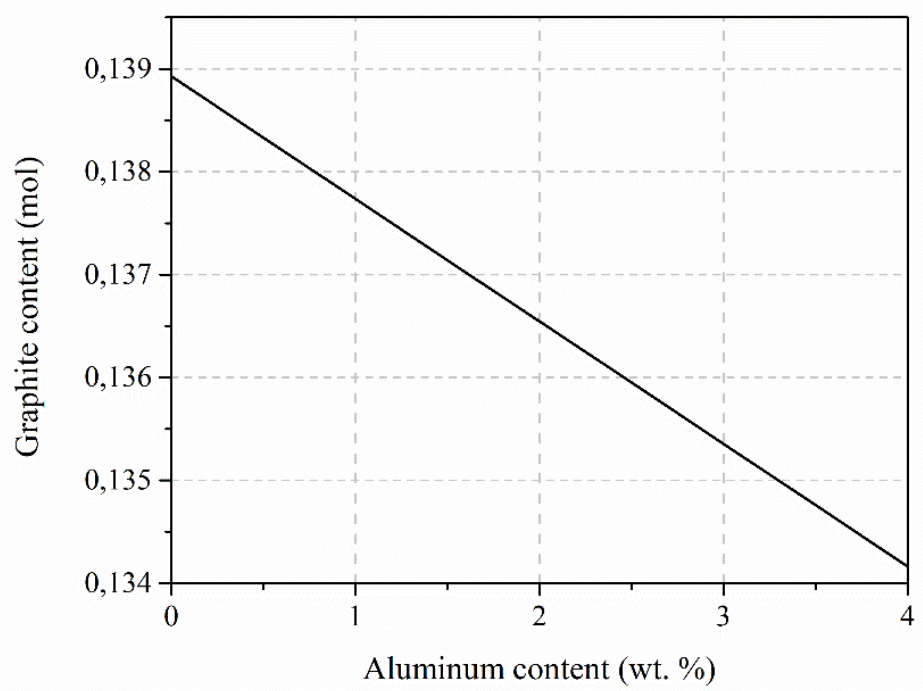

Fig. 4. Change of graphite content as a function of aluminum addition. 


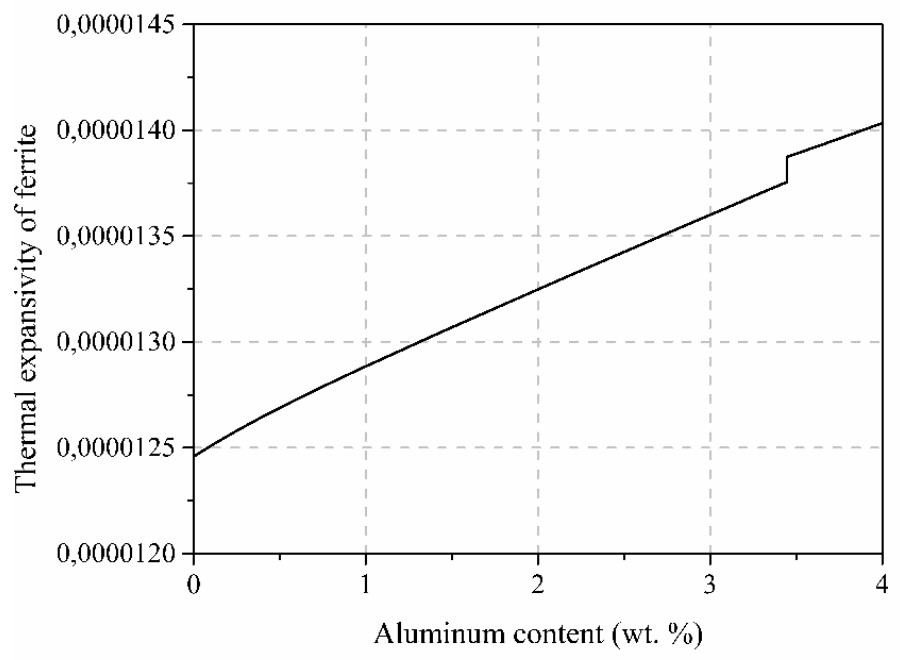

Fig. 5. Change in thermal expansivity of ferrite at RT with aluminum addition.

Solidification sequences of the studied compositions are given in Figure 6. Solidification starts with graphite precipitation and is completed by austenite transformation. Figure 6 also denotes that the solidification temperature changes from $1292{ }^{\circ} \mathrm{C}$ to $1450{ }^{\circ} \mathrm{C}$ with aluminum additions from 0 to 4 wt. $\%$.

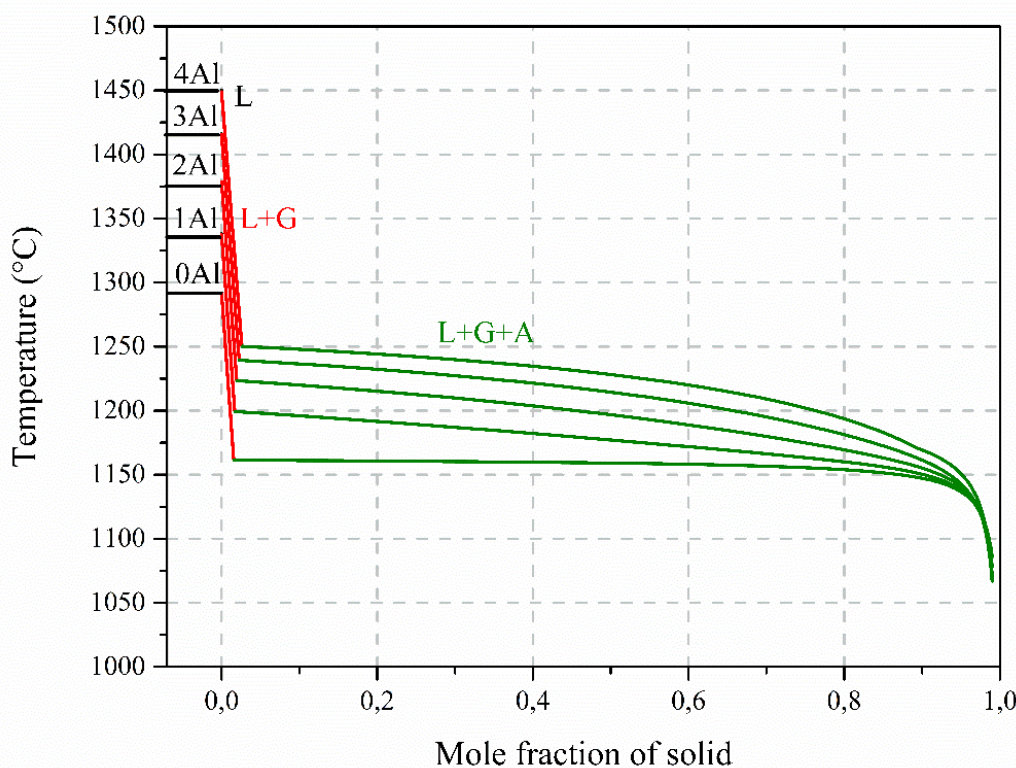

Fig. 6. Solidification paths of 3.5C-4Si-1W-xAl alloys. 
All transformation temperatures of the alloys, calculated by Thermo-Calc studies, are given in Table 1. The notations for the temperatures are as follows: $\mathrm{T}_{\mathrm{G}}$ indicates the start temperature of graphite precipitation from the liquid phase that also denotes the start of solidification, $\mathrm{T}_{\mathrm{AS}}$ indicates the start temperature of austenite formation from the liquid phase, $\mathrm{T}_{\mathrm{AF}}$ indicates the finish temperature of austenite formation also denoting the completion of solidification, $\mathrm{T}_{\mathrm{F}}$ indicates the start temperature of ferrite, and $\mathrm{T}_{\mathrm{M} 6 \mathrm{C}}$ indicates the start temperature $\mathrm{M}_{6} \mathrm{C}$ carbide precipitation. The calculated values indicate that all transformation temperatures shift to higher values by aluminum addition.

Table 1. Critical temperatures of cast irons calculated by Thermo-Calc studies $\left({ }^{\circ} \mathrm{C}\right)$.

\begin{tabular}{lcccccc}
\hline Alloy & $\mathrm{T}_{\mathrm{G}}$ & $\mathrm{T}_{\mathrm{AS}}$ & $\mathrm{T}_{\mathrm{AF}}$ & $\mathrm{T}_{\mathrm{F}}$ & $\mathrm{T}_{\mathrm{M} 6 \mathrm{C}}$ & $\mathrm{A}_{1}$ \\
\hline $0 \mathrm{Al}$ & 1292 & 1161 & 1085 & 907 & 978 & 853 \\
$1 \mathrm{Al}$ & 1338 & 1199 & 1077 & 950 & 988 & 889 \\
$2 \mathrm{Al}$ & 1379 & 1223 & 1070 & 985 & 998 & 917 \\
$3 \mathrm{Al}$ & 1416 & 1239 & 1137 & 1017 & 1002 & 939 \\
$4 \mathrm{Al}$ & 1450 & 1250 & 1170 & 1048 & 997 & 960 \\
\hline
\end{tabular}

\section{Microstructural characterization}

Before microstructural characterization, the chemical compositions of fully solidified cast alloys were determined by OES. Table 2 shows the chemical compositions of the cast alloys and they are in the required range as designed. The LM images of the polished cast samples are given in Figure 7 to investigate the graphite content and morphology. The quantified data by image analysis are given in Figure 8 and Table 3. According to Figure 8, as aluminum content increases, graphite content (area \%) decreases and similar results were obtained by Thermo-Calc calculations. The graphite morphology changes from spheroidal (VI) to irregular spheroidal (V) and vermicular (III) as aluminum content increases (Table 3 ). These results are in agreement with the current literature in terms of the aluminum effect on the graphite morphology in ductile cast irons [22]. Ibrahim et al. presented that the addition of 3 wt.-\% Al to SiMo ductile cast iron decreased the nodularity of graphite. Due to non-homogeneous and irregular accumulation of aluminum around the graphite nodules, a non-uniform diffusion of carbon is revealed resulting in deformed graphite morphology [25]. Lithium also emphasizes this effect and the reported data suggested that the deterioration effect of aluminum could be decreased by using a nodularizer combining magnesium with rare earth metals in the melt treatment [27].

Table 2. Chemical compositions of the cast alloys obtained by OES (wt.-\%).

\begin{tabular}{lcccccccc}
\hline Alloy & C & Si & W & Al & Mg & Mn & P & S \\
\hline $0 \mathrm{Al}$ & 3.57 & 4.04 & 0.96 & 0.02 & 0.074 & 0.231 & 0.0579 & 0.0282 \\
$1 \mathrm{Al}$ & 3.46 & 3.96 & 0.97 & 0.97 & 0.082 & 0.235 & 0.0597 & 0.0285 \\
$2 \mathrm{Al}$ & 3.47 & 3.99 & 1.03 & 2.03 & 0.078 & 0.245 & 0.0572 & 0.0321 \\
$3 \mathrm{Al}$ & 3.52 & 4.07 & 1.02 & 3.05 & 0.081 & 0.225 & 0.0581 & 0.0287 \\
$4 \mathrm{Al}$ & 3.54 & 4.05 & 1.04 & 4.03 & 0.079 & 0.228 & 0.0558 & 0.0355 \\
\hline
\end{tabular}




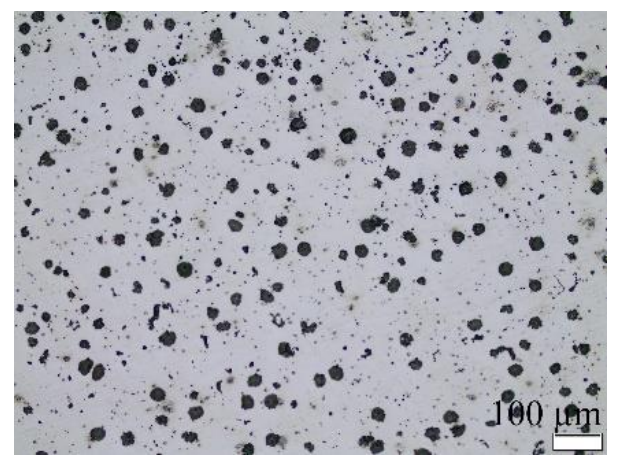

(a)

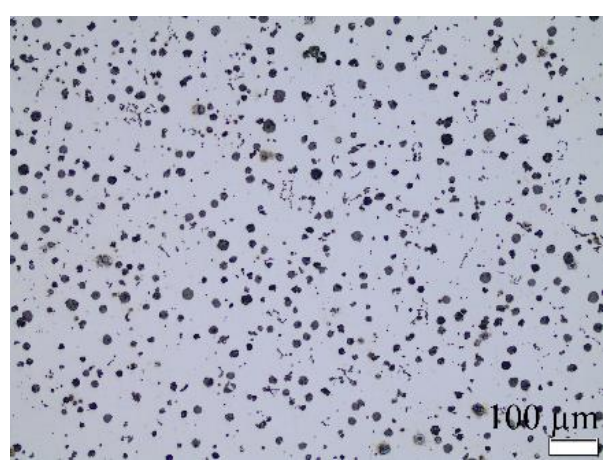

(b)

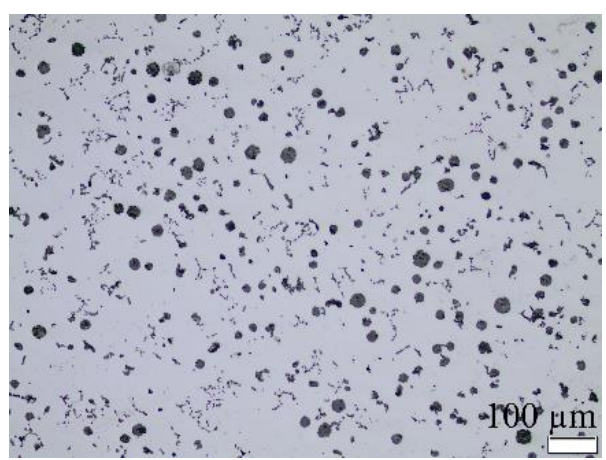

(d)

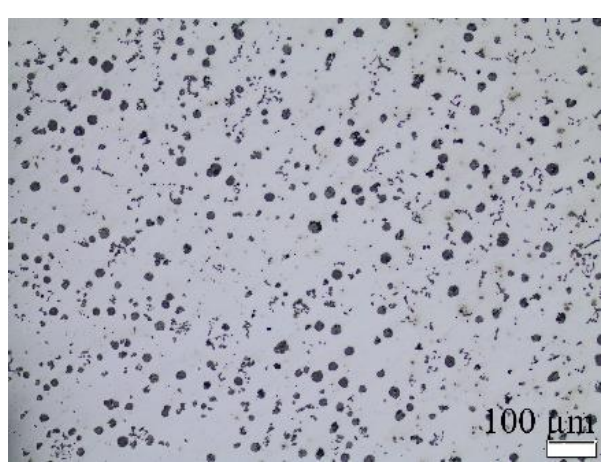

(c)

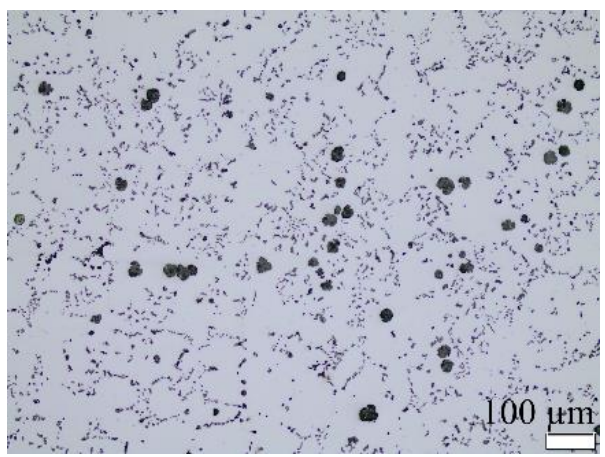

(e)

Fig. 7. LM images showing the graphite morphology in polished cast irons (a) OAl, (b) $1 \mathrm{Al}$, (c) 2Al, (d) $3 \mathrm{Al}$ and (e) $4 \mathrm{Al}$. 
Table 3. Image analysis results for graphite morphology as determined by DIN EN ISO 945-2 (area \%).

\begin{tabular}{|c|c|c|c|c|}
\hline Alloy & III & $\mathrm{V}$ & VI & Others \\
\hline 0Al & 6.0 & 49.6 & 40.7 & 3.7 \\
\hline $1 \mathrm{Al}$ & 8.6 & 40.3 & 46.5 & 4.6 \\
\hline $2 \mathrm{Al}$ & 15.0 & 45.3 & 32.1 & 7.6 \\
\hline $3 \mathrm{Al}$ & 15.1 & 41.7 & 36.6 & 6.6 \\
\hline $4 \mathrm{Al}$ & 20.7 & 41.3 & 25.5 & 12.5 \\
\hline
\end{tabular}

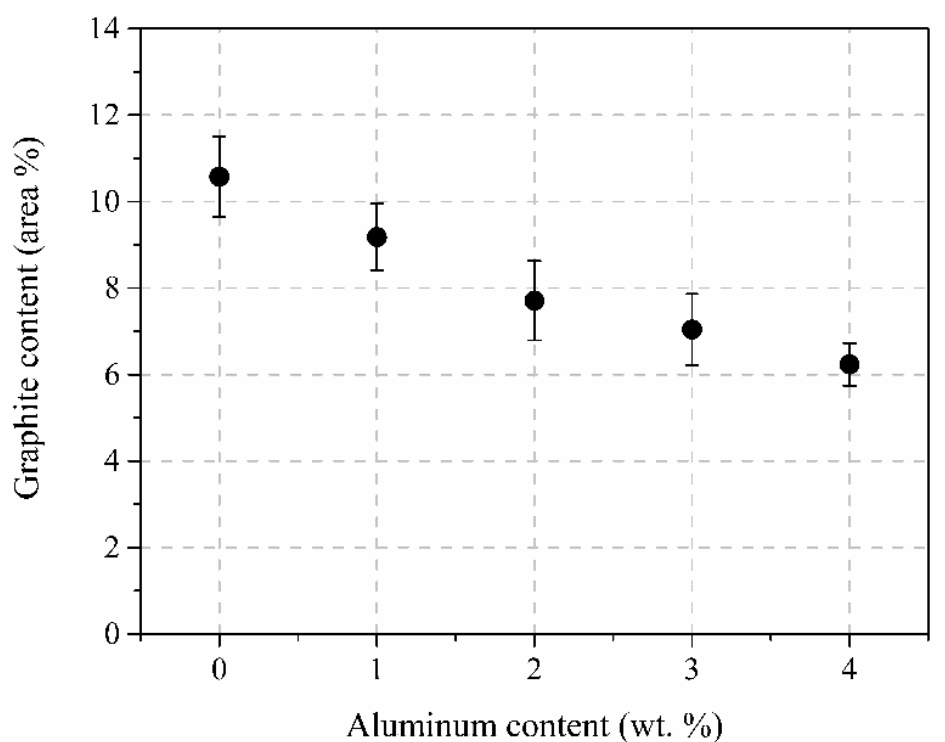

Fig. 8. Change of the graphite content by aluminum addition.

The microstructures of $0 \mathrm{Al}$ and $4 \mathrm{Al}$ are given in Figure 9. The microstructural features of the studied alloys consist of graphite, pearlite, coarse and skeleton-like carbides embedded in the ferritic matrix. In order to clarify the details of the pearlite region and coarse carbides within the matrix of $0 \mathrm{Al}$, an SEM image at higher magnification is inserted in Figure 9a. Such pearlitic formations can be seen in cast irons like SiMo ductile cast alloys [25, 28,29] having similar C and Si contents as 0Al. However, since aluminum addition prohibits the formation of pearlite [25], not only the amount of pearlite decrease but also its lamellar morphology changes to a structure having 
dispersed cementite. This effect was observed in the microstructure of $4 \mathrm{Al}$ as seen in Figure 9b. EDS analyses of coarse carbides revealed the composition as $61.2 \mathrm{~W}-17.9 \mathrm{C}$ 17.3Fe-3.6Si wt.- $\%$ indicating that they were $\mathrm{W}_{6} \mathrm{C}$ carbides. In order to confirm the phases, XRD studies were carried out and the data for $0 \mathrm{Al}$ and $4 \mathrm{Al}$ are given in Figure 10 and XRD spectra validate all phases present in the microstructure.

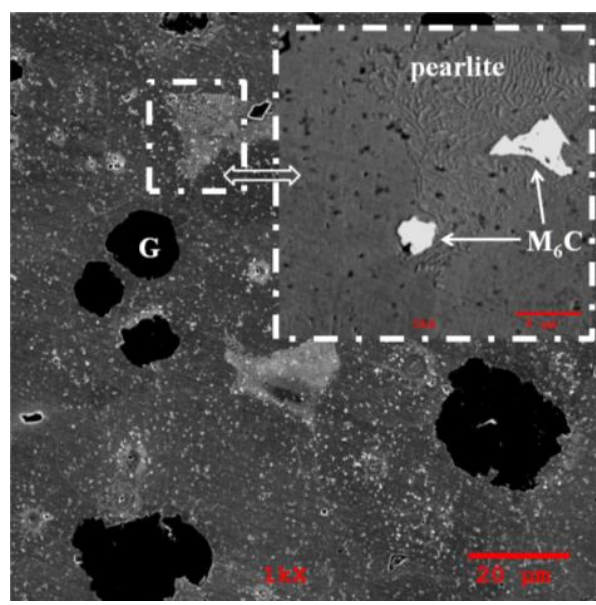

(a)

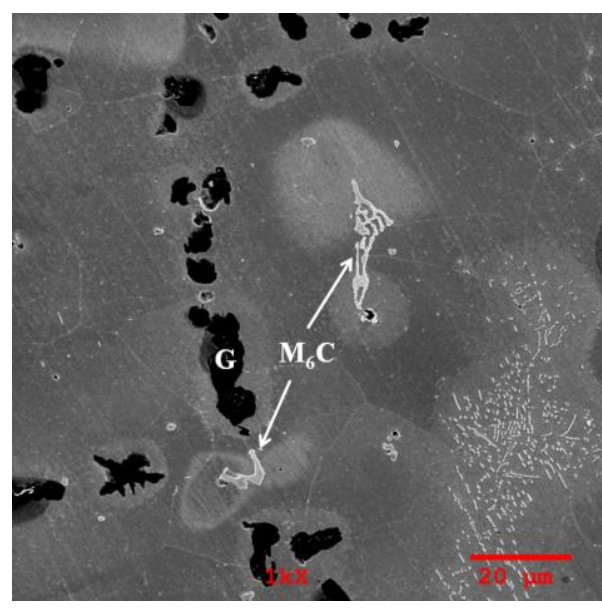

(b)

Fig. 9. SEM images showing the microstructure of the cast alloys; (a) OAl and (b) 4Al.

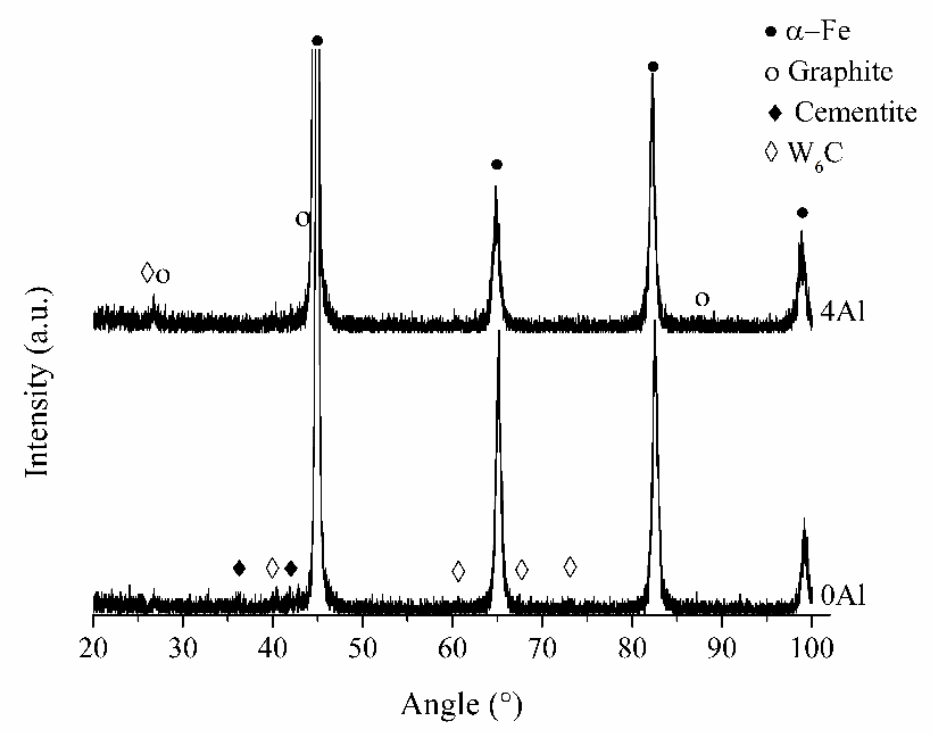

Fig. 10. XRD patterns OAl and $4 A$ l cast irons. 


\section{Evaluation of phase transformations by DTA}

The DTA data indicating the transformation temperatures for the heating condition is given in Figure 11 and resulting data are tabulated in Table 4. In the DTA thermogram, the results only for the specimens $0 \mathrm{Al}, 2 \mathrm{Al}$ and $4 \mathrm{Al}$ are given for clarity and the others show similar behavior. The notations for temperatures given in Table 4 are the same as the ones in Table 2. The DTA results indicate that all transformation temperatures shift towards higher temperatures and $\mathrm{A}_{1}$ temperature reaches as high as $981{ }^{\circ} \mathrm{C}$ for the highest aluminum addition. Thermo-Calc data (Table 2) indicated the same trend as DTA results (Table 4) and the calculated temperatures (CT) were close to those observed by thermal analysis. The small discrepancy between the calculated and measured temperatures could be since actual compositions of the cast alloys include $\mathrm{Mn}, \mathrm{Mg}, \mathrm{P}, \mathrm{S}$, and other trace elements that do not exist in the Thermo-Calc calculations.

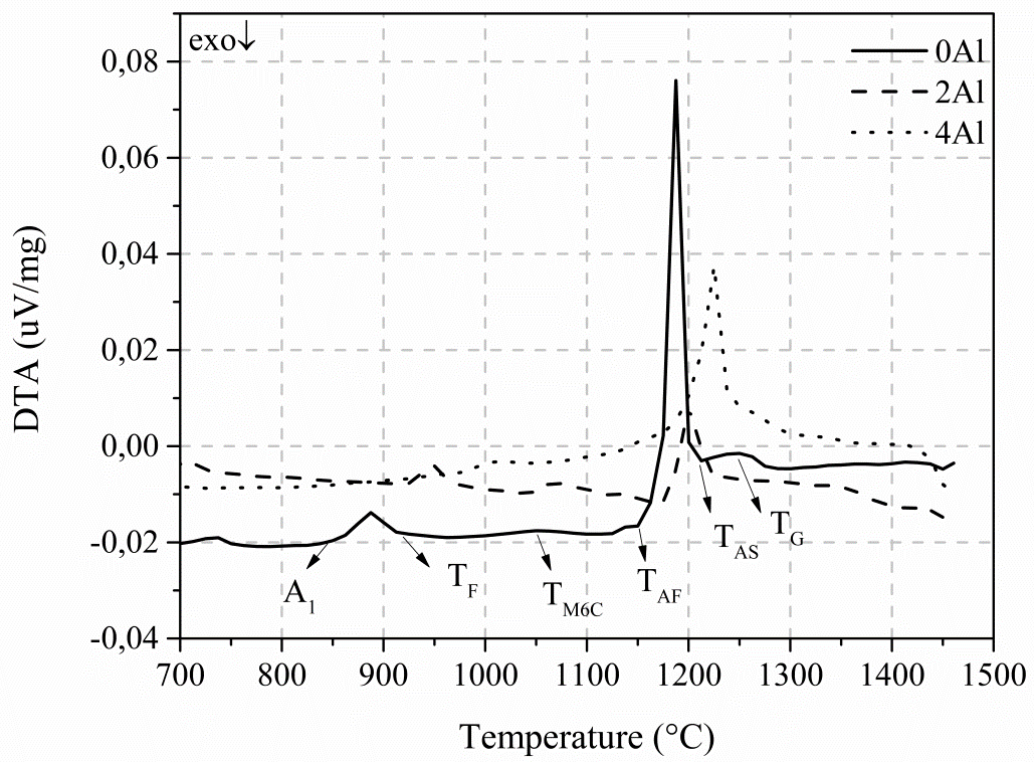

Fig. 11. Thermogram of the cast irons upon heating for $0 \mathrm{Al}, 2 \mathrm{Al}, 4 \mathrm{Al}$.

Table 4. Critical temperatures of cast irons identified by calculations and DTA analyses $\left({ }^{\circ} \mathrm{C}\right)$.

\begin{tabular}{lcccccccccccc}
\hline \multirow{2}{*}{ Alloy } & \multicolumn{2}{c}{$\mathrm{T}_{\mathrm{G}}$} & \multicolumn{2}{c}{$\mathrm{T}_{\mathrm{AS}}$} & \multicolumn{2}{c}{$\mathrm{T}_{\mathrm{AF}}$} & \multicolumn{2}{c}{$\mathrm{T}_{\mathrm{F}}$} & \multicolumn{2}{c}{$\mathrm{T}_{\mathrm{M} 6 \mathrm{C}}$} & \multicolumn{2}{c}{$\mathrm{A}_{1}$} \\
\cline { 2 - 12 } & $C T$ & $D T A$ & $C T$ & $D T A$ & $C T$ & $D T A$ & $C T$ & $D T A$ & $C T$ & $D T A$ & $C T$ & $D T A$ \\
\hline $0 \mathrm{Al}$ & 1292 & 1247 & 1161 & 1195 & 1085 & 1180 & 907 & 908 & 978 & 1053 & 853 & 863 \\
$1 \mathrm{Al}$ & 1338 & 1343 & 1199 & 1206 & 1077 & 1187 & 950 & 946 & 988 & 1050 & 889 & 905 \\
$2 \mathrm{Al}$ & 1379 & 1333 & 1223 & 1221 & 1070 & 1185 & 985 & 964 & 998 & 1071 & 917 & 931 \\
$3 \mathrm{Al}$ & 1416 & 1350 & 1239 & 1224 & 1137 & 1196 & 1017 & 974 & 1002 & 1056 & 939 & 940 \\
4Al & 1450 & 1402 & 1250 & 1237 & 1170 & 1209 & 1048 & 1114 & 997 & 1053 & 960 & 981
\end{tabular}




\section{Conclusion}

In this study, thermodynamic calculations with Thermo-Calc software on novel ductile cast iron compositions $3.5 \mathrm{C}-4 \mathrm{Si}-1 \mathrm{~W}-x \mathrm{Al}$ where $x$ varies between $0-4$ (wt. \%) were carried out and results were validated by experimental studies on cast samples to reveal the possibility of its use in place of commercial ferritic ductile cast irons at more demanding working conditions. Thermo-Calc calculations revealed that; (i) the stable phases at RT were ferrite, graphite and $\mathrm{M}_{6} \mathrm{C}$ carbide for all compositions, (ii) with increasing aluminum additions, $\mathrm{A}_{1}$ temperature increased, graphite content decreased and thermal expansivity increased, (iii) according to the solidification sequence, solidification started with graphite precipitation for all compositions however it is completed by austenite transformation for $0,1,2 \mathrm{wt}$. \% Al, whereas by ferrite transformation for 3 and 4 wt. \% Al. Experimental studies showed that; (i) the stable phases at RT were ferrite, graphite and $\mathrm{W}_{6} \mathrm{C}$ carbide for all aluminum added compositions as indicated by ThermoCalc, (ii) graphite content decreased by aluminum addition as indicated by calculations and its morphology changed from spheroidal to vermicular and (iii) $A_{1}$ temperatures increased as aluminum increased in heating thermograms and they were very close to those calculated by Thermo-Calc.

\section{Acknowledgment}

The authors, G. Aktaş Çelik, Ş. Polat and Ş. H. Atapek, wish to acknowledge the financial support given by the Scientific Research Projects Coordination Unit of Kocaeli University under the project no $2017 / 118$.

\section{References}

[1] A. A. Partoaa, M. Abdolzadeh, M. Rezaeizadeh: J Cent South Univ, 24 (2017) 546-559.

[2] [G.M. Castro Güizaa, W. Hormaza, A.R. Galvis E, L.M. Méndez Moreno: Eng Fail Anal, 82 (2017) 138-148.

[3] Y. Zhang, M. Li, L. A. GodlewskI, J. W. Zindel, Q. Feng: Metall Mater Trans A, 47A (2016) 3289-3294.

[4] M. Ekström, S.Jonsson: Mater Sci Eng, A 616 (2014) 78-87.

[5] M. Ekström, P. Szakalos, S. Jonsson: Oxid Met, 80 (2013) 455-466.

[6] F. Tholence, M. Norell: Oxid Met, 69 (2008) 37-62.

[7] J. P. Shingledecker, P. J. Maziasz, N. D. Evansa, M. J. Pollard: Int J Press Vessels Pip, 84 (2007) 21-28.

[8] Y. Zhang, M. Li, L. A. Godlewski, J. W. Zindel, Q. Feng: Mater Charact, 139 (2018) 19-29.

[9] H. Inoue, T. Koseki: Acta Mater, 124 (2017) 430-436.

[10] M. Górny: Arch Foundry Eng, 8:3 (2008) 59-64.

[11] D. Holmgren, A. Diószegi, I. L. Svensson: Int J Cast Met Res, 20:1 (2007) 30-40.

[12] Z.J. Ma, D. Tao, Z. Yang, Y.C. Guo, J.P. Li, M.X. Liang, L. T. Li Yeung: Materials and Design, 93 (2016) 418-422.

[13] X Wu, G. Quan, R. Macneil, Z. Zhang, X. Liu, C. Sloss: Metall Mater Trans A, 46:6 (2015) 2530-2543.

[14] L. M. Åberg, C. Hartung: Trans Indian Inst Met: 65:6 (2012) 633-636.

[15] G. E. Totten, Steel Heat Treatment, second ed. Portland, Longman, New York, 2006. 
[16] A. I. Al-Ghonamy, M. Ramadan, N. Fathy, K. M. Hafez, A. A. El-Wakil: Int J Civil \& Env Eng IJCEE-IJENS, 10:03 (2010) 1-5.

[17] H. Nakayama, B.-R. Zhao, N. Furusato, S. Yamada, T. Nishi, H. Ohta: Mater Trans, 59: 3 (2018) 412-419.

[18] T. Sjögren, I. L. Svensson: Metall Mater Trans A, 38:4 (2007) 840-847.

[19] R. González-Martíneza, U. de la Torrea, J. Lacazeb, J. Sertuch: Mater Sci Eng A, 712 (2018) 794-802.

[20] N. Haghdadi, B. Bazaz, H.R. Erfanian-Naziftoosi, and A.R. Kiani-Rashid: Int J Miner Metall Mater, 19:9 (2012) 812-820.

[21] A. Shayesteh-Zeraati, H. Naser-Zoshki, A.R. Kiani-Rashid: J Alloys Compd, 500 (2010) 129-133.

[22] M.S. Soiński, A. Jakubus, G. Stradomski: Arch Foundry Eng, 13:2 (2013) 163168.

[23] M. Górny and M. Kawalec: J Mater Eng Perform, 22:5 (2013) 1519-1524.

[24] T. N. F. Souza, R. A. P. S. Nogueira, F. J. S. Franco, M. T. P. Aguilar, P. R. Cetlin: Mat Res, 17:5 (2014) 1167-1172.

[25] M. M. Ibrahim, A. Nofal, M.M. Mourad: Metall and Mater Trans B, 48:2 (2017) 1149-1157.

[26] A. Alhussein, M. Risbet, A. Bastien, J. P. Chobaut, D. Balloy, J. Favergeon: Mater Sci Eng A, 605 (2014) 222-228.

[27] D. Li: Metall and Mater Trans B, 49B (2018) 858-859.

[28] P. Matteis, G. Scavino, A. Castello, D. Firrao: Procedia Mater Sci, 3 (2014) $2154-2159$.

[29] B. Cygan, M. Stawarz, J. Jezierski: Arch Foundry Eng, 18-4 (2018) 103-109.

\section{(c) (†) Creative Commons License}

This work is licensed under a Creative Commons Attribution 4.0 International License. 